(2) This hydrolysis, and consequently the error, is reduced to a minimum when the inversion of the sucrose present is effected by heating for ten minutes, the temperature being gradually raised so as to reach $68^{\circ}$ at the expiration of this time.

(3) The results with the different glucoses are sufficiently uniform to warrant the introduction of a correction for the mean error.

(4) In order that the results may be comparable, chemists ought to strictly adhere to one method of inversion.

UHu, STRF T'NIVI:RSIT,

Com,rasts, Orto.

\title{
ON THE ACTION OF ACETIC AND HYDROCHLORIC ACIDS ON SUCROSE.
}

BY H. A. WEABR AND WILLIAM MCPHERSON

$W^{\text {HILE carrying out some experiments with glucose sev- }}$ eral facts were noted in reference to the action of acetic and hydrochloric acids on sucrose, which it is interesting to compare with the conclusions reached by Bornträger, ${ }^{1} \mathrm{Jung}$ fleisch and Grimbert, ${ }^{2}$ and Ost. ${ }^{3}$ Inasmuch as we were working with an entirely different object in view, the conclusions reached were in no way influenced by the conclusions reached by the above writers.

While making an examination of a large number of saccharine products, the writers were led to believe from certain results that complete inversion could be effected by means of acetic acid. This view was contrary to the general opinion of chemists, although as prominent ones as Jungfleisch and Grimbert ${ }^{4}$ claim that acetic acid completely inverts sucrose at $100^{\circ}$, and that it is preferable to other acids, since its presence is without effect upon the levulose of invert sugar. This conclusion was reached from the fact that the specific rotatory power of pure levulose corresponded almost exactly with that of levulose calculated from invert sugar, the inversion being effected by acetic acid. Hydrochloric acid gives a higher invert reading, because, in some way, it acts upon the levulose and increases very percepti-

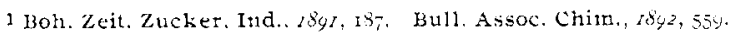

2 Compt. rend., 107, 390, and 108, i44.

8 Ber. d. chem. Ges., $24,1636$.

4 Compt. rend., 107, 390. 
bly, its specific rotatory power. Exceptions to this view are taken by Maumené, ${ }^{1}$ who calls attention to the fact that the invert sugar prepared from sucrose by action of acids is not composed of equal parts of levulose and dextrose. Ost ${ }^{2}$ not only denies that acetic acid will produce complete inversion, but also claims that it acts perceptibly upon invert sugar. Ross ${ }^{3}$ states, as the result of a number of experiments, that it was found impossible to secure complete inversion even when ten per cent. glacial acid was used and the flask kept immersed in boiling water for forty-five minutes.

Those who claim that acetic acid does not effect complete inversion base their belief upon the fact that invert sugar, prepared by the action of hydrochloric acid upon sucrose, gives a higher reading than the corresponding solution obtained by the action of acetic acid. It was thought that perhaps acetic acid might form some compound with the constituents of the invert sugar, which might affect the reading of the polariscope. Proceeding upon this assumption, attempts were made to decompose such a compound. In the course of these experinents, which were conducted at great length, certain facts were noted which have been systematized in the following:

As stated above, Jungfleisch and Grimbert in particular, have called attention to the fact that the specific rotatory power of invert sugar, prepared by the action of hydrochloric acid on sucrose, is higher than that of the artificially made invert sugar. If, however, as Maumené claims, the invert sugar so prepared is not composed of equal parts of dextrose and levulose, then it is possible that the different readings are due to the peculiar compounds formed. In fact, one would not expect the readings to be identical under such assumptions.

Accordingly, experiments were undertaken to find out, if possible, whether the hydrocliloric acid used in inversion affected in any way by its presence the reading of the invert sugar so prepared. Attempts were made in two different directions.

I. Five hundred cc. of a normal solution of sucrose (polariz-

1 Journal des Fabricants de Sucre. Abstract from March 27, 1889.

2 Ber. d. chem. Ges., $24,1636$.

8 Report of the Association of Official Agricultural Chemists, Bul. 35, Div. of Chem., Dept. Agr., p. 146. 
ing at 99.8) was subjected to inversion in $100 \mathrm{cc}$. flasks by adding one-tenth the volume of concentrated hydrochloric acicl (sp. gr. I.I9) and heating for ten minutes, regulating the heat so that the temperature, $68^{\circ}$, was reached at the end of that tine. These solutions were all poured into a large flask and thoroughly mixed, so as to obtain a perfectly uniform solution. Exactly fifty-five cc. of this solution were transferred to a roo-rio cc. flask, the flask filled to the nark with water, the solution thorotighly mixed and polarized. The experiment was repeated with the addition of five cc. of the same acid used in the inversion, previous to filling to the mark with water; again repeated with the addition of ten $c c$., fifteen $c c$. and twenty $c c$, respectively. Since the same solutions, same flasks, and polarizing tubes were used, and the temperature of the solutions did not differ more than $0.5^{\circ}$, corrections being introduced for this variation the chances of error in manipulation were rery slight. The following readings, expressed in divisions of cane-sugar scale, were obtained for the various solutions (temperature $=20^{\circ}$ ):

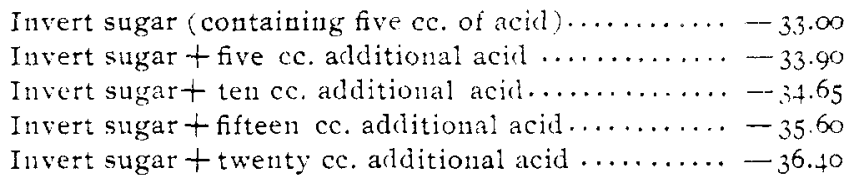

The reading is seen to increase with the addition of the acid, thus agreeing with the conclusion of Gubbe.' Moreover, the deviations caused by the addition of the different amounts of acid are fairly constant, varying from 0.75 to 0.95 , or an average of 0.85 . It was hoped that sufficientiy uniform results could be obtained to allow the graphic representation, so that an estimate could be made on the effect of the original five cc. of acid added to bring about inversion. Since, however, the addition of a second, third, fourth, and fifth five cc. of acid each increases the reading of the invert sugar approximately 0.85 , then we nay conclude, with some probability, that the original five cc. of acid which effected the inversion would increase the reading by that amount.

2. Attempts were also made to solve the problen by neutral-

1 Ber d. chen. Ges., $18,2207$. 
izing the acid present in the invert solution by the action of sodium carbonate.

Bornträger' has called attention to the fact that the rotatory power of the neutralized solution is higher than that of the corresponding acid solutions. By the addition of sodium carbonate, however, not only is the acid neutralized, but a corresponding amount of sodium chloride is thereby added. Readings were taken first to find out the effect of the addition of the sodium chloride. Then, by comparing this with the variation caused by neutralization with sodium carbonate, the effect of the acid could be deduced.

Five hundred cc. of inverted sugar solution were prepared as described above. It was found that three and three-tenths grams of pure dry sodium carbonate were necessary to neutralize the acid (five cc.) present in fifty-five cc. of this solution. The experiments were conducted as in the above. Fifty-five cc. of the solution were transferred to a (I00-I IO) flask, neutralized with sodium carbonate, the flask filled to the mark, the solution mixed thoroughly and polarized. The duplicates agreed within the limit of error in reading. The average readings on canesugar scale were as follows (temperature $=20^{\circ}$ ):

$$
\begin{aligned}
& \overbrace{\text { I. } \quad \text { Triplicates. }}^{\text {T. }} \\
& \text { Original solution............... -33.I }-33.0-33.20 \\
& \text { Original solution }+3.3 \text { grams sodium } \\
& \text { carbonate (neutral) } \ldots \ldots \ldots \ldots \ldots \ldots-33.7-33.7 \quad-33.85 \\
& \text { Original solution }+6.6 \text { grams sodium }
\end{aligned}
$$

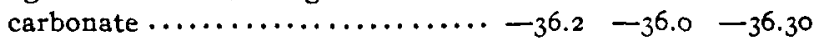

The last reading was taken in order to compare the effects of the addition of sodium carbonate before and after neutralization. It is thus seen that, while the reading of the normal solution is increased $0.6^{\circ}$ by the addition of the necessary amount of carbonate to neutralize the acid, the subsequent addition of a like amount increases the reading $2.5^{\circ}$. Before ascribing this difference in reading to the effect of the acid, it is necessary to find whether or not the sodium chloride, formed by the addition of the sodium carbonate to hydrochloric acid, affected the reading

Experiments were conducted with the same solution used

1 Boh. Zeit. Zucker, Ind., 1891, 187. 
above. Fifty-five cubic centimeters of the solution were introduced into the Ioo-r Io cc. flask, and the amount of sodium chloride corresponding to three and three-tenths grams of sodium carbonate, or 3.65 , added, the flask filled and the solution polarized as before. The average readings on cane-sugar scale, agreeing within $0 . \mathrm{I}^{\circ}$, are:

Original solution........................ $-33.1-33.15$

Origival solution +3.65 grams sodium chloride. $-35.1-35.10$

Since, then, the effect of the sodium chloride was to increase the reading $2^{\circ}$, the acid remaining unneutralized, while the reading was only increased $0.6^{\circ}$ by the addition of the same amount of sodium chloride, the acid heing neutralized at the same time, the difference $r .4^{\circ}$ may presumably be attributed to the action of the acid present.

This result is higher than the one deduced from the direct addition of acid given above, but it is undoubtedly the more correct of the two. It would thus seem that the acid undoubtedly increases the rotatory power, the probable increase of reading being about $1.4^{\circ}$ on the direct scale for the normal solution.

Similar experiments were next conducted in order to find out the effect of acetic acid. The strength of the acid used may be inferred from the fact that five cc. of it required for neutralization 3.05 grams of ary sodium carbonate. The normal solution of sucrose was heated at $100^{\circ}$ with one-tenth rolume of this acid for about one hour, experiments showing that continued heating had but little effect upon the reading. By this treatment a reading for the normal solution was obtained on an arerage of $2^{\circ}$ lower than when hydrochloric acid was used as the agent of inversion. The same solution which gave a reading of $-33.1^{\circ}$ when hydrochloric acid was used gave a reading of -3 I. I when treated with acetic acid under the above conditions.

Experiments performed to discover whether the subsequent addition of acetic acid would affect the reading, gave the following results, on cane-sugar scale :

Original invert solution (temperature 20 ............ - $31.10-3$ r.o Original invertsolution + ten $c c$. additional acetic acill... $-30.85-30.8$

The second reading is the reading obtained from a solution exactly the same as the first ten cc. of acetic acid being introduced. 
It thus appears that while hydrochloric acid increases the reading by its presence, acetic acid decreases it by a small but perceptible amount. This result agrees with Ost, who criticises the statement of Jungfleisch and Grimbert that acetic acid has no effect upon invert sugar. In order to test this further, the acid was neutralized by sodium carbonate and the difference of reading noted. This result, united with the effect due to the introduction of the sodium acetate formed, gave the means of finding the effect of the acid.

The experiments were conducted as in the above, using same solution, same flasks, and same polarizing tubes. The following are the results obtained, on cane-sugar on scale :

Original solution (temperature $\left.20^{\circ}\right) \ldots \ldots \ldots \ldots \ldots \ldots \ldots-3$ I.20 -3 I.I Original solution +3.05 grams sodium carbonate (neutral) $-32.65-32.6$ Original solution $+(3.05 \times 2)$ grams sodium carbonate.. - $34.80-34.8$

A marked difference is noted here as compared with similar experiments with hydrochloric acid. The neutralization of the hydrochloric acid increased the reading only $0.6^{\circ}$, while the neutralization of the acetic acid increased the reading over twice the amount, or $1.5^{\circ}$. The subsequent effects of the sodium carbonate upon the two solutions agree very well, being an increase of $2.5^{\circ}$ in the case of hydrochloric acid against an increase of $2.2^{\circ}$ in the case of acetic acid. This difference of $0.3^{\circ}$ in the reading is accounted for by the fact that 3.3 grams of sodium carbonate were added in the hydrochloric acid solution, while only 3.05 grams were added in the acetic acid solution. If correction be made for this difference, the increase in readings differ only by $0.1^{\circ}$.

It was necessary also to find out the effect of the sodium acetate formed by the netutralization of the acetic acid by sodium carbonate. The readings on the cane-sugar scale were as follows :

Original solution (temperature $\left.20^{\circ}\right) \ldots \ldots \ldots \ldots \ldots-3$ I.I -3 I.I

Original solution $+4.7^{2}$ grams sodium acetate... $-32.4-32.4$

The sodium acetate used was the pure anhydrous salt.

It is thus seen that while the sodium carbonate increased the reading $1.5^{\circ}$, the introduction into the original solution of the same amount of sodium acetate as was formed increased the 
reading but $1.3^{\circ}$. The difference of $0.2^{\circ}$ must be due to the presence of the acid.

The conclusion that the acetic acid by its presence lowers sliglitly the reading is confirmed by the fact that by the use of a weaker acid a maximum reading of $-31.3^{\circ}$ was obtained.

As might be expected the introduction of hydrochloric acid into a solution inverted by acetic acid increases the reading in a corresponding degree.

It is thus shown that the effect of hydrochloric acid upon a solution of invert sugar is to increase the reading, while acetic acid has an opposite effect. Moreover, the experiments show that the probable increase in reading due to hydrochloric acid uncter the conditions mentioned is $1.4^{\circ}$, while the probable decrease in reading due to acetic acid is $0.2^{\circ}$. In other words, if these two acids produced the same effects upon being heated with sucrose, there would still be a difference of reading of $1.6^{\circ}$ due to the presence of the acid. This agrees fairly well with the actual difference observed.

In the light of these experiments it may be of interest to notice the question so often discussed, "Does acetic acid effect conplete inversion?" If we suppose that no açid effects complete inversion unless it gives a reading such as that obtained by using hydrochloric acid, then most certainly acetic acid does not invert completely. If, on the other hand, we adopt as the reading of the invert solution the reading of the acid solution, corrected for the effect produced by the presence of the acid, then acetic acid gives more nearly the correct invert reading, and it is correct to affirm that acetic acid does invert sucrose completely.

Finally, the above results indicated that when Fehling's solution is used in the place of the polariscope, it would be a matter of indifference whether acetic or hydrochloric acid was used to effect the inversion of the sucrose. Experiments showed this to be true. Two solutions containing the same amount of sucrose were inverted with hydrochloric and acetic acids respectively. After inversion exactly I I.7 cc. of each solution were required to reduce ten cc. of Fehling's solution. Moreover, when Fehling's solution is used for the determination of sucrose in presence of dextrin or commercial glucose, acetic acid is preferable to hydro- 
chloric acid as the agent of inversion, since the process requires no attention, and the error introduced by the hydrolysis of dextrin is less even when the most favorable method of inversion is used; viz., heating for ten minutes, regulating the temperature so as to reach $68^{\circ}$ at the expiration of that time.

OHIO STATE Uiviversity,

COLUMBUS, OHIO.

\section{METHOD OF DETERMINING CHROMIUM IN CHROME ORE.}

BY Fidund Clark.

Received February 8, I895.

DROF. STORER and others have suggested the use of nitric acid and potassium chlorate as agents for the oxidation of chromic compounds to chromic acid. Using this suggestion as a basis for the determination of chromium in chrome iron ore, I have experimented with a method which has proved both practicable and accurate.

For complete analysis a half gram sample of the finely ground ore is weighed into a platinum crucible with a capacity of not less than fifty $\mathrm{cc}$. The ore is covered with twenty-five grams of potassium bisulphate and fusion is commenced over a Bunsen burner with very low flame which is protected from air currents by a sheet iron chimriey.

To insure complete fusion, and to guard against any loss, the operator must manipulate carefully and watch the operation from beginning to end. At first, the flame should be so low as to fuse the bisulphate very slowly.

After the mass is in a liquid condition, and there is no longer any danger of loss from spattering, the crucible is grasped with a pair of crucible tongs and the contents are run up around the sides, in order to seize hold of any particles of ore which may have become stranded there.

At this stage of the process, the flame may be increased a little so as to cause a tolerable redness of the bottom of the crucible.

At intervals of ten minutes the crucible must be manipulated by the operator as before described. Forty minutes will suffice for complete decomposition of the ore. Pour the contents into a perfectly clean and dry, four to five-inch platinum evaporating 